\title{
Análisis histórico de la profesión de las finanzas en Puerto Rico desde 1898 hasta 2010
}

\author{
Ángel L. Rivera Aponte | angrivera@upr.edu \\ Universidad de Puerto Rico, Recinto de Río Piedras \\ Lourdes Cádiz Ocasio | lourdes.cadiz1@upr.edu \\ Universidad de Puerto Rico, Recinto de Río Piedras \\ Lorena Gely Rojas | lorena.gely@upr.edu \\ Egresada de la Universidad de Puerto Rico, Recinto de Río Piedras
}

Recibido en: 18 de febrero de 2015

Aceptado en: 23 de noviembre de 2015

\section{RESUMEN}

El presente estudio es una investigación cualitativa de corte histórico, sobre la evolución de la profesión de las finanzas desde 1898 hasta 2010, en Puerto Rico. Encontramos que la disciplina de las finanzas fue desagregada en sus ofrecimientos académicos, a escala de educación superior. Además, como parte del proceso económico de un país las finanzas se desarrollaron y crecieron de acuerdo a las exigencias del mercado industrial y laboral, en los títulos de las ocupaciones. Descubrimos que la profesión de las finanzas es dominada por el género femenino; sin embargo, el estudio demuestra que existe una brecha salarial en la mayoría de las ocupaciones de este campo, en contra del género femenino.

Palabras clave: profesión de finanzas, ocupaciones en las finanzas, análisis histórico laboral, oferta académica en finanzas, Puerto Rico.

\section{ABSTRACT}

This study presents an historical descriptive analysis on the evolution of the finance profession in Puerto Rico, from 1898 until 2010. We found that the finance discipline was disaggregated regarding the academic programs offered at the higher education level. Moreover, as part of a country's economic process finance discipline developed and grew due to the requirements of the labor and industrial markets in terms of the titles of occupations. We found that females dominate the profession of finance; however, the study demonstrates a level of wage gap among most of the occupations in this professional field against females.

Keywords: finance profession, financial occupations, labor market-historical analysis, finance degree offerings, Puerto Rico. 
Las dinámicas del mercado laboral y la participación de la academia en este ambiente nos llevaron a estudiar cuidadosamente el campo de las finanzas en cuanto a su origen, desarrollo y crecimiento, en y fuera de Puerto Rico. Esta disciplina se desarrolló como parte de la economía en Estados Unidos a finales del siglo XIX; sin embargo, como campo de estudio independiente surgió a principios del siglo XX, según Del Valle y Schemel (2011). Esta estrecha relación entre una y otra disciplina de estudio se encuentra todavía en su propia definición. El Diccionario de Empresa y Economía la describe como "una rama de la economía que estudia los mercados de dinero y de capitales" (2007, p. 309). Por su parte, Oliverio (2007) la identifica como un área especializada que estudia todos los aspectos de adquirir dinero y la toma de decisiones sobre su distribución. También hay relación en los precursores de la disciplina. Identificamos a Irving Fisher, economista matemático norteamericano que dedicó su carrera a estudiar teorías relacionadas con el dinero y la economía, y se le considera el padre de la economía monetaria por sus principales contribuciones (Pressman, 1999, pp. 91-93).

Los primeros centros de educación superior en Estados Unidos especializados en la disciplina surgieron con la Escuela Wharton de Finanzas y Comercio de la Universidad de Pennsylvania en 1881, para ofrecer un grado académico en Finanzas y Economía, y en el 1906 con la Escuela de Comercio, Cuentas y Finanzas de la Universidad de Nueva York (Roque Delgado, 1976, pp.7-8). La disciplina como se conoce en la modernidad, se desarrolló durante la década de 1950 con dos vertientes: Finanzas para Administración de Empresas y Finanzas Económicas (Miller, 1999, p. 95). La Economía, en especial la Microeconomía, sirvió como piedra angular para el desarrollo de las finanzas corporativas en la década de 1950. De este campo de estudio nuevo y especializado surgen las profesiones de las finanzas tal como las conocemos hoy en día. Los profesionales de estas son personas que se dedican a la consultoría, la intermediación, la comercialización, el análisis, la divulgación de la información sobre la banca y los seguros, la bolsa y los fondos de inversión. 
El desarrollo de la profesión en Puerto Rico fue identificado a través del catálogo y del prospecto del 1902-1903, realizados por el Departamento de Educación, Escuela Normal Insular de Puerto Rico. Uno de sus programas se ofreció en la Universidad de Puerto Rico (UPR). En el programa de estudio del primer año escolar, el primer curso de Economía fue dictado por el doctor W. G. Wood. Dicho curso se inició a mediados de 1910 y formó parte de los cursos de Microeconomía de la Facultad de Ciencias Sociales. Luego, para 1926, el Colegio de Administración Comercial comenzó a ofrecer cursos de la disciplina de finanzas. Algunos de estos fueron: Principios de Moneda y Banca (Economía 51-52, seis horas); Finanzas de Negocios (Economía 53, tres horas); Inversiones (Economía 54, tres horas); Finanzas Públicas (Economía 55-56, seis horas); y Procedimientos Bancarios (Economía 65-66, cuatro horas).

Dadas las exigencias del mercado laboral en Puerto Rico, el Colegio de Administración Comercial presentó a la Junta Universitaria de la UPR una propuesta para generar una concentración en Finanzas. El 28 de octubre de 1964 la Junta Universitaria de la UPR en Río Piedras, aprobó una nueva concentración en finanzas para el Bachillerato en Administración Comercial (que sustituye la que aparece en el Boletín informativo del Colegio de Administración Comercial-Año 1962-63). Esta concentración en Finanzas fue la primera en toda la Isla y pionera en el campo académico.

Los objetivos de este estudio son: identificar y analizar los componentes que impulsaron el campo de las finanzas como profesión u ocupación en Puerto Rico desde su origen académico, analizar la evolución de la fuerza laboral durante el periodo de 1898 a 2010 y la desagregación por género y salario, para identificar si existe o no brecha salarial. La escasa revisión de literatura, la ausencia de los datos y la incertidumbre sobre el origen de la disciplina en la Isla nos brindó la oportunidad de desarrollar este estudio de corte histórico sobre el campo de las finanzas. Presentamos un panorama general del origen y la evolución de las finanzas como disciplina y el desarrollo de la fuerza laboral en el campo. 


\section{ReVISIÓn De Literatura}

La historia financiera está directamente relacionada con el desarrollo comercial de un país, el desarrollo de la moneda y el surgimiento de la banca a través de la historia mundial. Finel-Honigman (2010) describe este desarrollo como:

Money, its mutable value, weight, and convertibility into goods or other types of coinage or currency, was always seen as mysterious, only available to a chosen few. From the moneychangers in the temple to medieval usurers, Wall Street speculators, the latest evil doers, and oil futures speculators, financial transactions needed an esoteric set of skills, numerical at best, alchemic at worst, in order to be able to understand and profit from the complexities of price differentials, fees, commissions and changing valuations. A purview of how money was viewed through the ages illustrated the universality and the immutability of these perceptions. (p. 17).

Actualmente, el sector industrial de las finanzas y los seguros es un área especializada de la economía con un gran poder, y en diferentes periodos históricos mundiales impactó y sigue impactando positiva o negativamente a los países y a sus ciudadanos. La revisión de literatura nos permitió identificar sucesos históricos que impulsaron el desarrollo económico en Europa, Estados Unidos y Puerto Rico para presentar la evolución de un sistema financiero que crea la necesidad de una fuerza laboral especializada. La literatura explica el sistema financiero como el conjunto de instrumentos, mercados e instituciones cuya función es canalizar el flujo de fondos (Enciclopedia financiera, 2015).

\section{Evolución históRICA en EUROPA}

Podemos identificar el inicio de las finanzas desde el comienzo de la civilización humana. En Mesopotamia, los sumerios y sus sucesores babilónicos perfeccionaron contratos para reglamentar el comercio, las finanzas y la propiedad privada (Barron \& Miranti, 
1997, p. 29). A través del comercio, estas ideas se propagaron por las tierras circundantes al Mar Mediterráneo. Durante el imperio grecorromano se crearon instituciones financieras que facilitaron la actividad económica, incluyendo el desarrollo de monedas, bonos de intercambio y nuevos modelos en las finanzas públicas. En la Edad Media y el Renacimiento las finanzas tuvieron un mayor auge. Finel-Honigman (2010) identifica el siglo XI como el período que ayudó a propagar el concepto y la aceptación de las monedas y las especies a través de los mercados, las ferias y las grandes concentraciones de centro urbanos (p.16).

Florencia y Venecia fueron la cuna del desarrollo de las finanzas por el auge económico de estas ciudades. En este ambiente surgieron los primeros bancos en Génova y Venecia (1171 y 1177, respectivamente). La recuperación económica y la formación del comercio internacional entre el norte y el sur de Europa dieron paso a la expansión del sector financiero. Con el comercio se desarrollaron nuevas prácticas como la conversión para el intercambio extranjero, monedas y bonos de intercambio, financiamiento de proyectos y la aceptación de depósitos. Es importante destacar que el desarrollo de la imprenta en Alemania coincidió con la creación de casas y prensa de monedas en Europa. Finel-Honigman (2010, p. 27) señala que a mediados del siglo XV la moneda francesa e inglesa se estandarizó; se establecieron bancos públicos en Italia y se expandieron las transacciones de bienes raíces mediante bonos de terrenos (land bonds).

Los grandes descubrimientos de tierras fueron otro elemento impulsador de una fuerza laboral relacionada con las finanzas. Del 1450 al 1720, los nuevos horizontes económicos crearon el ambiente adecuado para el establecimiento de compañías de intercambio (Barron \& Miranti, 1997, p. 55). En este avance estuvieron las sociedades de capital, las cuales fueron desarrolladas en Inglaterra con la English India Company (Barron \& Miranti, 1997, p. 56). El surgimiento de la industrialización (en el último cuarto del siglo XVIII) trajo nuevas instituciones financieras y en el siglo XIX se establecieron nuevos mercados financieros para subsidiar la expansión industrial (Barron \& Miranti, 1997, p. 124). Estas oportunida- 
des de inversión centradas en la manufactura y la transportación requirieron grandes cantidades de capital que fueron manejadas por las instituciones establecidas.

\section{Evolución hISTÓRICA en Estados Unidos}

La literatura sobre el desarrollo de las finanzas en Estados Unidos es abundante y en este estudio nos limitaremos a destacar el surgimiento de la corporación como forma de organización, la importancia de la bolsa de valores y el sistema de clasificación industrial como componentes importantes del sistema financiero de este país. Encontramos en los ensayos de Davis (citado en Oliverio, 2007) la existencia de corporaciones privadas establecidas con propósitos educativos, eclesiásticos y comerciales a finales del periodo colonial. Muchas fracasaron y perdieron la inversión de sus contribuciones y la respuesta gubernamental fue un acta (1791), para incorporar la Society for Establishing Useful Manufactures, empresa dedicada a la manufactura de papel, textiles y otros. Davis identificó esta empresa como la pionera de las corporaciones en Estados Unidos.

La primera bolsa de valores fue establecida en 1790 en Filadelfia y dos años más tarde se constituyó la bolsa de valores de Nueva York, NYSE, conocida como la más grande del mundo. Su primer cliente fue el Banco de Nueva York, en 1792. Esta tuvo un papel significativo en el financiamiento de las empresas con la compra y venta de títulos de valores (securities). El siglo XIX marcó un cambio en este sector industrial al integrar una mezcla de servicios financieros, que lo convierten en una industria sofisticada que minimizó los mercados financieros desarrollados en la Europa del siglo XVIII. Es en el siglo XIX cuando las corporaciones logran el éxito financiero por el desarrollo mercantil del País.

El siglo XX representó el máximo desarrollo económico de las finanzas, caracterizado por grandes crisis y éxitos financieros. La banca se expandió y adquirió un rol protagonista de control y poder financiero constituyendo el mayor componente de la industria a nivel global. Schumpeter, economista de renombre (citado en Oliverio, 2007) describe a los banqueros como la fuente de fondos 
de los empresarios, quienes frecuentemente carecen de recursos financieros. Destaca que la función principal del dinero o el mercado monetario es negociar el crédito para propósitos de desarrollo financiero. Oliverio señala que el economista reconocía la participación de los bancos americanos en el crecimiento de la economía desde la mitad del siglo XIX hasta las primeras décadas del siglo $\mathrm{XX}$, aunque el éxito trajo el elemento de alarma por el crecimiento de los monopolios y los abusos en los negocios (2007, p. 305).

El desarrollo histórico de las finanzas en este país creó un sector industrial fuerte identificado en un sistema de clasificación industrial, conocido por sus siglas en inglés como NAICS, a partir de 1997. Todas las empresas son agregadas dentro de industrias definidas por negocios que usan procesos de producción y servicios similares. Es la norma actual utilizada por las agencias federales que recopilan, analizan y publican datos estadísticos como el Negociado del Censo - para proveer datos relacionados con la economía del País - y el Negociado de Estadísticas Laborales (BLS, en inglés), para agrupar las ocupaciones por sector industrial. El NAICS tiene identificados 20 sectores industriales principales y el código 52 identifica el sector de las finanzas y los seguros con 88 sectores desagregados.

\section{Desarrollo económico de Puerto Rico y su sistema financiero}

En este breve recorrido histórico, observamos cómo el desarrollo económico de un país impulsa su sistema financiero y a su vez este crea ocupaciones para atender a sus sectores industriales. El desarrollo económico de Puerto Rico fue frágil y limitado desde su colonización hasta los años 1940, lo que afectó la evolución del sistema financiero, su sector industrial y la necesidad de ocupaciones en las finanzas. El desarrollo financiero y la acumulación de activos financieros en un país reflejan una división en producción, ahorros, inversiones e intermediarios (Maldonado, 1970, p. 8). Este desarrollo financiero en Puerto Rico se caracterizó por la fuga de la moneda y de capital.

Los investigadores consultados (Di Venuti, 1950; Rivera Rodríguez, 1991; Santiago De Curet, 1989) coinciden en identificar la 
moneda y la falta de capital como los principales obstáculos del sistema financiero en Puerto Rico. En su libro Money $\mathcal{E}$ banking in Puerto Rico, Di Venuti (1950) describe la economía de la Isla, centrada en la agricultura desde 1537, fecha en que se agotó el oro. El suelo era cultivable para la caña de azúcar y los esclavos fueron la mano de obra para desarrollar la industria del azúcar. Paralelamente, en el País se desarrolló el contrabando en los siglos XVI, XVII y XVIII fuera de San Juan. Se utilizaba la producción local del tabaco y el café para intercambiarla por las necesidades de la población. El contrabando proveyó las necesidades de los locales y estimuló la producción hasta inicios del siglo XIX. Su desarrollo es explicado por Santiago De Curet (1989), destacando que las principales naciones europeas aprovecharon los desatinos financieros de España para consolidar y ampliar el comercio clandestino en Puerto Rico. El comercio legal era limitado al puerto de San Juan y los productos que se redistribuían al resto de la Isla eran más caros. El resultado fue el enriquecimiento de un grupo de oficiales y comerciantes que no invertían sus caudales en la Isla (p. 11). La autora enfatiza que el asentamiento de extranjeros no fue un elemento de progreso económico, porque propiciaron la fuga de la moneda y obstaculizaron la formación y reinversión de capitales, como ilustra el ejemplo de la familia Overmann (pp.14-16).

El situado fue la moneda oficial del siglo XIX, procedente de México, hasta su independencia en 1810. Era utilizada para el pago y sostenimiento del Gobierno y la milicia (Di Venuti, 1950; Martínez Soto, 2012; Santiago De Curet, 1989). Simultáneamente, circularon también piezas de varios orígenes y dudoso valor legal (Santiago De Curet, 1989, p. 20). La moneda era poca y la que circulaba no era confiable, elementos suficientes para obstaculizar la movilidad de los productos y la formación de capitales locales. La situación financiera se complicó con la eliminación del situado, porque aumentaron los gastos del Gobierno y para resolverlo emitieron las papeletas en 1812 por la Junta de Hacienda de Puerto Rico (Di Venuti, 1950, p. 5); más tarde se eliminaron por cambios políticos en España. 
La España de principios del siglo XIX fue invadida por Napoleón en 1810; Carlos IV y Fernando VII abdicaron y José Bonaparte asumió el trono español. El pueblo español luchó por su soberanía y posteriormente se estableció un gobierno provisional que benefició a Puerto Rico, porque solicitó un representante en el Gobierno para cada provincia. El representante de Puerto Rico fue Ramón Power, quien nombró al primer intendente Alejandro Ramírez en 1813. Este estableció un programa de reformas económicas: eliminación de las papeletas, renovación de las aduanas, introducción del peso macuquino, renovación de la Sociedad Amigos del País y la publicación del Diario Económico (Di Venuti, 1950; Martínez Soto, 2012). Además, la Cédula de Gracia de 1815 y el Código de Comercio de 1829 fueron normas de la metrópoli aplicadas en la Isla para estimular el comercio y el desarrollo de sociedades y corporaciones mercantiles, para la elite comercial y agrícola (Martínez Soto, 2012, p. 222) de cafe y tabaco.

El sistema monetario de la España del siglo XIX fue bimetálico, a diferencia de los principales países europeos que se regían por el oro, y sus colonias sintieron el impacto de la desorganización y la confusión monetaria del período. El siglo XIX fue problemático para Puerto Rico en términos de su moneda y la oferta monetaria en general (Rivera Rodríguez, 1991, p. 1). La moneda macuquina fue introducida al País por emigrantes venezolanos en 1810 y en el 1813 fue autorizada por el gobernador Marchesi (Di Venuti, 1950; Santiago De Curet, 1989), quien también decretó la admisión de monedas extranjeras en circulación. Santiago De Curet (1989) explica que estas medidas se tomaron para resolver el "problema de escasez de moneda en la Isla y cinco años después circulaban monedas norteamericanas, francesas y mejicanas” ( $p$. 26). La macuquina causó problemas porque se falsificaba en Estados Unidos y se importaba por "Santomas" mediante los puertos de Mayagüez, Ponce y Guayama. La autora explica en sus investigaciones que "Santomas" fue proveedor de manufactura europea y fuente de crédito para Puerto Rico. Destaca la autora que "la relación no se limitó al comercio, sino que tomó parte en el financiamiento de la agricultura. La falta de capitales en Puerto Rico 
determinó que los capitales de "Santomas" se trasladaran a la Isla (p. 39). La macuquina circuló hasta que el gobierno metropolitano la devaluó en 1857.

Por otra parte, Martínez Soto (2012) describe otros mecanismos financieros de la agricultura comercial en un Puerto Rico articulados "en una economía sin bancos, en la que otros agentes financieros jugaron un papel crucial, comerciantes-banqueros, pequeños comerciantes locales, casas de comercio internacional, suministradores de maquinarias y otros" (p. 219). En este escenario de necesidades de financiación identificó a "el refaccionista", comerciante que financiaba las cosechas mediante préstamos con altas tasas de interés y obligaba a los hacendados a comprarle los abastecimientos a precios elevados y vender la producción a precios inferiores (pp. 221-222). Los principales obstáculos que limitaron el crédito de los agricultores fueron: la falta de estructura para registrar los derechos de propiedad que impidieron el desarrollo hipotecario y el poco respaldo de España para el establecimiento de un banco agrícola.

Otro problema relacionado con la moneda surgió de 1870 a 1880 con la circulación del peso mexicano en Puerto Rico (Rivera Rodríguez, 1991; Santiago De Curet, 1989). Di Venuti (1950) lo identifica como la moneda oficial en el 1876 y Rivera Rodríguez (1991) lo ubica en el 1879. Los estudiosos del tema indican que la abundancia de la moneda se debió al pago de compensaciones a los hacendados por la abolición de la esclavitud en 1873. Existió un consorcio europeo que negoció la compra de bonos a los hacendados durante los años 1876 al 78 y la llamaron la negociación Hermua, (Di Venuti, 1950; Rivera Rodríguez, 1991; Santiago De Curet, 1989). El problema con la moneda fue la especulación de su valor; se compraba fuera de Puerto Rico a precios más baratos y la traían a un precio mayor que en el resto del mundo, con la aceptación del gobierno local (Rivera Rodríguez, 1991, p. 5). Esto causó controversias en diversos sectores de la sociedad del siglo XIX. Una de ellas fue en 1886, cuando se unieron comerciantes de la Unión Mercantil, el Círculo Mercantil y la Sociedad Anónima de Crédito Mercantil, para solicitar la prohibición a los bancos locales a emitir 
papel moneda y retomaron el tema del banco de emisión y descuento. La autora destaca que en este siglo no había evolucionado el derecho exclusivo de acuñación del Gobierno y la aceptabilidad del papel moneda (Rivera Rodríguez, 1991, p. 20).

Di Venuti (1950, p. 12) comenta que la banca surge como respuesta a estas necesidades económicas del País. El autor identifica cuatro instituciones bancarias entre 1888 y 1895: Banco Español de Puerto Rico, Banco Territorial y Agrícola, Banco Popular y el Banco Crédito y Ahorro Ponceño. El siglo XIX cierra en Puerto Rico con la Guerra Hispanoamericana en 1898 y el cambio de soberanía. Así se complica más el sistema monetario, por el alto volumen de monedas diversas en circulación, hasta que Estados Unidos establece el Acta Orgánica de 1900 y se retiran las monedas que circulaban para sustituirlas por el dólar (Di Venuti, 1950, p.15). Señala el autor que los comerciantes norteamericanos fueron atraídos por las oportunidades de lucro en la Isla con el resultado de un "strong ímpetus to banking" y un aumento en el uso de las facilidades financieras (p. 25). La necesidad y el tiempo trajeron la instalación de agencias de crédito del gobierno federal tales como: Federal Housing Administration, Reconstruction Finance Corporation, Postal Savings System, unidades de la Farm Credit Administration y la Farmers Home Administration.

La economía mejoró durante la Primera Guerra Mundial a partir de 1915. Debido a los altos precios del azúcar y el ingreso que generó este bien, aumentaron los negocios y la banca experimentó gran actividad, financiando las transacciones mercantiles y agrícolas. En 1919, el Tesorero Insular (citado en Di Venuti, 1950) identificó el registro de 236 corporaciones domésticas y 150 extranjeras. Concluye Di Venuti (1950) que Puerto Rico tuvo beneficios completos del mecanismo monetario de Estados Unidos; sin embargo, la mayoría de los hombres de negocios mantenían sus capitales y créditos en los bancos de Estados Unidos. La guerra termina y la economía cambió.

En 1920 bajó el precio del azúcar en Puerto Rico. En 1928 surgen pérdidas millonarias por el huracán San Felipe, la caída de la bolsa en Estados Unidos en 1929 y el azote del huracán San Ciprián 
en 1932. Todo esto provoca una depresión económica en la Isla. En ese momento, la Reconstruction Finance Corporation adquiere un rol importante para la economía de la Isla por la inyección de fondos al País (Di Venuti, 1950, p. 30). Posteriormente hay dos consecuencias en la economía local: el Reciprocal Trade Agreements Act de 1934 y el Sugar Act de 1937, con lo cual se redujo la producción del azúcar. Maldonado (1970) concluye que las primeras tres décadas del régimen americano trajeron capital y el producto nacional aumentó; sin embargo, no cambió la pobreza de la Isla en sectores como la salud y el empleo —inestable-, los cuales, en conjunto con el rápido crecimiento de la población, impidieron un mejoramiento del nivel de vida (p. 24).

En este panorama económico, la agricultura constituyó la única actividad hasta 1940. Maldonado (1970) explica que la evolución de una economía agraria a una industrializada está fundamentada en un desarrollo autónomo y espontáneo del sector privado y para que dichos esfuerzos emerjan y sean implementados tiene que existir unidad política nacional cohesiva de propósito. Ninguno de estos factores existía en el Puerto Rico de 1940. Se inició la Operación Manos a la Obra y en 1942 se creó la estructura para el programa de industrialización (p. 25). En este ambiente surge el sector de la manufactura en el que se expandieron otras áreas como: servicios, comercio, servicios gubernamentales y construcción. Luego, los diferentes modelos económicos generaron cambios y transformaciones aceleradas a finales del siglo XX y al comienzo del siglo XXI. En los últimos años, por los impactos de la economía globalizada, se generaron y desaparecieron industrias y ocupaciones, y se crearon y modificaron las ofertas académicas relacionadas con la disciplina de las finanzas dentro y fuera de Puerto Rico.

\section{Metodología}

Esta es una investigación cualitativa que presenta un análisis de corte histórico sobre la profesión de las finanzas en Puerto Rico, desde el 1898 hasta el 2010. En el estudio se analiza la evolución de oferta académica, ocupación, sexo y salarios en Puerto Rico. Un 
análisis de corte histórico es una investigación descriptiva que comprende estudiar el comportamiento, las tendencias, los fenómenos y trayectorias de una separación de hechos basados en distintos periodos de tiempos (Denzin y Lincoln, 2008). Pretendemos recopilar y evaluar diversos datos relacionados con la profesión utilizando las estadísticas censales de Puerto Rico (demanda) y el banco de datos de los ofrecimientos académicos (oferta) de las instituciones de educación superior en la Isla.

La fuente principal de datos fue constituida por los documentos de los archivos del Consejo de Educación de Puerto Rico. Los datos examinados se clasificaron por programas académicos a nivel subgraduado y graduado, y por niveles académicos: grados asociados, bachilleratos, maestrías, doctorados y certificados a nivel universitario para el campo de las finanzas.

Debemos mencionar para propósito de esta investigación lo siguiente: en términos académicos, todos los programas a nivel de educación superior relacionados con la disciplina de las finanzas fueron aprobados por el Consejo de Educación Superior de Puerto Rico (CESPR). La base de datos que se utilizó en esta investigación fue producto de la lista de programas existentes oficialmente certificados por el CESPR, de todas las instituciones públicas y privadas solamente de Puerto Rico, desde 1903 hasta 2011. Cabe señalar que, dada la diversidad de programas académicos en la disciplina de las finanzas, se agregaron de acuerdo a la institución académica que ofrece la especialidad. La disciplina de las finanzas es una agregación de diversidad de programas académicos tanto a nivel subgraduado (grados asociados y bachilleratos) como graduado (maestrías y doctorados).

La segunda fuente de datos fueron los documentos del Departamento de Comercio de Estados Unidos de América, Negociado del Censo Federal, Censo de Población de Puerto Rico (de 1898, 1910, 1920, 1930, 1935, 1940, 1950, 1960, 1970, 1980, 1990, 2000 y 2010). Información adicional fue solicitada a la Oficina del Censo Federal, la Oficina del Censo de Puerto Rico, la Junta de Planificación de Puerto Rico y la Universidad de Puerto Rico. De esas fuentes, se recopilaron los datos concernientes a la clasificación ocupacional 
detallada del grupo trabajador civil diestro y de las personas empleadas por sexo y salario, para determinar la fuerza laboral en la profesión de las finanzas. Esta base de datos se utiliza con el objetivo de identificar la demanda del mercado laboral de la profesión de finanzas. En términos del mercado laboral, esta profesión es la suma de la agregación de todas las ocupaciones relacionadas con este campo de estudio.

Las ocupaciones se organizaron utilizando el Sistema de Clasificación Ocupacional de Estados Unidos desde el 1898 hasta el 2010, usando diferentes niveles de agregación: el grupo ocupacional principal, los subgrupos ocupacionales y el detalle de cada una de las ocupaciones. La gran cantidad de las ocupaciones registradas en Puerto Rico a través de las décadas, los cambios en los nombres de las clasificaciones y los códigos que establecen los estándares de clasificaciones ocupacionales, requirieron uniformar la base de datos. Cada una de las ocupaciones se clasificó a través de las décadas. La cantidad de estas fluctuó entre 500 y 650. Después de identificar los códigos y definiciones establecidos en el manual de clasificación ocupacional, se agregaron las ocupaciones dividiéndolas en diferentes categorías, lo que resultó en una agregación de 113 subgrupos ocupacionales. Estos a su vez se reagruparon en 13 grupos ocupacionales principales: ocupaciones ejecutivas, administrativas y gerenciales; profesionales; técnicas y de apoyo técnico; vendedores; de apoyo administrativo, oficinistas, secretarias y otros; de servicios; de agricultura, silvicultura y pesca; reparadores y mecánicos; trabajadores diestros en la construcción; ocupaciones en trabajos de precisión; operarios de transportación y ocupaciones relacionadas con el movimiento de materiales y trabajadores de la construcción y otros obreros. Una vez completada la recopilación y clasificación de los datos, se realizó el análisis de los cambios en los empleos del campo de las finanzas en Puerto Rico, por género y salario. Además, se analizaron los datos para determinar la existencia de brecha salarial por género en las ocupaciones relacionadas con el campo de las finanzas en Puerto Rico, para la década de 2000.

Como se indicó en el estudio, en Puerto Rico desde 1898, en el primer censo de población realizado por Estados Unidos, ya 
existían personas que trabajaban en ocupaciones relacionadas con la profesión de finanzas. Después, en la década del 1960, se creó el primer programa oficial de esta disciplina. Este programa se creó en la UPR, en Río Piedras. Dicho programa se gestó por la necesidad de preparar profesionales que reunieran los requisitos laborales que exigía el mercado de empleo en Puerto Rico.

Por otra parte, debemos indicar que los últimos datos oficiales del BLS relacionados con el salario promedio para Puerto Rico, para las 1,800 ocupaciones, fueron recopilados el año 2000. Los datos que aparecen después del censo del 2000 para Puerto Rico no se pueden agregar debido al cambio en el Diccionario de Ocupación de Empleo de los Estados Unidos para la Isla; por ende, los salarios para el 2010 no se pueden utilizar para propósito del estudio.

\section{AnÁLISIS}

\section{Desarrollo de la Profesión en LA EDUCACIÓn SUPERIOR}

El desarrollo de la profesión de las finanzas se nutre de los programas académicos a nivel de educación superior. Los programas académicos constituyen el lado de la oferta laboral. Los programas académicos son un conjunto de asignaturas, materias $u$ ofrecimientos educativos organizados por disciplinas, de tal forma que da derecho a quien lo completa satisfactoriamente a recibir de la institución que lo ofrece un reconocimiento académico oficial, producto del estudio formal, ya sea de nivel subgraduado o graduado (Oficina del Registrador, UPR, Recinto de Mayagüez, s.f.). Los cursos de finanzas en Puerto Rico se originan en los cursos de Economía de las Ciencias Sociales. La oferta académica en finanzas continuó desarrollándose a partir de la década de 1960 en otras instituciones de educación superior. Según a lista de programas certificados por el CESPR desde 1903 hasta 2011, existen unos 42 programas académicos relacionados con las finanzas en ocho instituciones de educación superior en la Isla (véase la Tabla 1). 
Tabla 1

Cantidad de programas académicos relacionados con la disciplina de las finanzas, según los niveles académicos en instituciones de educación superior en Puerto Rico, desde 1903 hasta 2011

\begin{tabular}{|c|c|c|c|c|c|}
\hline \multirow[b]{2}{*}{$\begin{array}{l}\text { Nombre de la } \\
\text { institución }\end{array}$} & \multicolumn{2}{|c|}{ Subgraduado } & \multicolumn{2}{|c|}{ Graduado } & \multirow{2}{*}{$\begin{array}{c}\text { Total de } \\
\text { Programas } \\
\text { Académicos }\end{array}$} \\
\hline & $\begin{array}{c}\text { Grados } \\
\text { Asociados }\end{array}$ & $\begin{array}{l}\text { Bachille- } \\
\text { ratos }\end{array}$ & $\begin{array}{l}\text { Maes- } \\
\text { trías }\end{array}$ & $\begin{array}{l}\text { Docto- } \\
\text { rados }\end{array}$ & \\
\hline $\begin{array}{l}\text { Bayamón Central } \\
\text { University }\end{array}$ & 0 & 0 & 1 & 0 & 1 \\
\hline Caribbean University & 9 & 0 & 0 & 0 & 9 \\
\hline $\begin{array}{l}\text { Instituto de Banca y } \\
\text { Comercio }\end{array}$ & 2 & 0 & 0 & 0 & 2 \\
\hline $\begin{array}{l}\text { National University } \\
\text { College }\end{array}$ & 0 & 2 & 0 & 0 & 2 \\
\hline $\begin{array}{l}\text { Sistema de } \\
\text { la Pontificia } \\
\text { Universidad Católica }\end{array}$ & 0 & 1 & 2 & 0 & 3 \\
\hline $\begin{array}{l}\text { Sistema Universidad } \\
\text { de Puerto Rico }\end{array}$ & 0 & 7 & 2 & 1 & 10 \\
\hline $\begin{array}{l}\text { Sistema Ana G. } \\
\text { Méndez }\end{array}$ & 0 & 1 & 0 & 0 & 1 \\
\hline $\begin{array}{l}\text { Sistema de la } \\
\text { Universidad } \\
\text { Interamericana }\end{array}$ & 3 & 4 & 7 & 0 & 14 \\
\hline Total & 14 & 15 & 12 & 1 & 42 \\
\hline
\end{tabular}

Fuente: Consejo de Educación Superior de Puerto Rico.

De estos, unos 29 programas académicos son a nivel subgraduado y los restantes 13 son a nivel graduado. Unos 32 programas académicos se concentran en 7 instituciones universitarias privadas en Puerto Rico. Los restantes 10 programas académicos se ofrecen en el Sistema de la UPR. Esta es la única institución postsecundaria que ofrece un programa doctoral en esta disciplina. La institución universitaria con mayor número de programas en finanzas es el Sistema de la Universidad Interamericana de Puerto Rico (UIPR), donde se ofrecen 14 programas académicos a nivel de grados asociados, bachilleratos y maestrías. 
Análisis histórico de la profesión de las finanzas en Puerto Rico desde 1898 al 2010

Tabla 2

Distribución porcentual de programas académicos relacionados con la disciplina de las finanzas por niveles académicos en instituciones de educación superior en Puerto Rico, desde 1903 hasta 2011

\begin{tabular}{|c|c|c|c|c|c|}
\hline \multirow[b]{2}{*}{$\begin{array}{l}\text { Nombre de la } \\
\text { institución }\end{array}$} & \multicolumn{2}{|c|}{ Subgraduado } & \multicolumn{2}{|c|}{ Graduado } & \multirow{2}{*}{$\begin{array}{c}\text { Total de } \\
\text { Programas } \\
\text { Académicos }\end{array}$} \\
\hline & $\begin{array}{c}\text { Grados } \\
\text { Asociados }\end{array}$ & $\begin{array}{l}\text { Bachille- } \\
\text { ratos }\end{array}$ & $\begin{array}{l}\text { Maes- } \\
\text { trías }\end{array}$ & $\begin{array}{l}\text { Docto- } \\
\text { rados }\end{array}$ & \\
\hline $\begin{array}{l}\text { Bayamón Central } \\
\text { University }\end{array}$ & $0.0 \%$ & $0.0 \%$ & $100.0 \%$ & $0.0 \%$ & $100.0 \%$ \\
\hline Caribbean University & $100.0 \%$ & $0.0 \%$ & $0.0 \%$ & $0.0 \%$ & $100.0 \%$ \\
\hline $\begin{array}{l}\text { Instituto de Banca y } \\
\text { Comercio }\end{array}$ & $100.0 \%$ & $0.0 \%$ & $0.0 \%$ & $0.0 \%$ & $100.0 \%$ \\
\hline $\begin{array}{l}\text { National University } \\
\text { College }\end{array}$ & $0.0 \%$ & $100.0 \%$ & $0.0 \%$ & $0.0 \%$ & $100.0 \%$ \\
\hline $\begin{array}{l}\text { Sistema de la Pontificia } \\
\text { Universidad Católica }\end{array}$ & $0.0 \%$ & $33.3 \%$ & $66.7 \%$ & $0.0 \%$ & $100.0 \%$ \\
\hline $\begin{array}{l}\text { Sistema Universidad } \\
\text { de Puerto Rico }\end{array}$ & $0.0 \%$ & $70.0 \%$ & $20.0 \%$ & $10.0 \%$ & $100.0 \%$ \\
\hline Sistema Ana G. Méndez & $0.0 \%$ & $100.0 \%$ & $0.0 \%$ & $0.0 \%$ & $100.0 \%$ \\
\hline $\begin{array}{l}\text { Sistema de la } \\
\text { Universidad } \\
\text { Interamericana }\end{array}$ & $21.4 \%$ & $28.6 \%$ & $50.0 \%$ & $0.0 \%$ & $100.0 \%$ \\
\hline Total & $33.3 \%$ & $35.7 \%$ & $28.6 \%$ & $2.4 \%$ & $100.0 \%$ \\
\hline
\end{tabular}

Fuente: Consejo de Educación Superior de Puerto Rico.

La Tabla 2 nos presenta la distribución porcentual de los programas académicos. El $69.0 \%$ de los programas académicos en la disciplina de finanzas son a nivel subgraduado. Las instituciones postsecundarias Caribbean University y el Instituto de Banca ofrecen el $100.0 \%$ de sus programas a nivel de grados asociados; en las instituciones National College y el Sistema Universitario Ana G. Méndez, el $100.0 \%$ de los ofrecimientos son a nivel de bachillerato. Es significativo que los ofrecimientos del Sistema de la UPR representan un $70.0 \%$, porque fue la primera institución a principios de siglo que inició esta oferta académica. En el Sistema de la Pontificia Universidad Católica (PUC) estos representan un $33.0 \%$ a nivel de ba- 
chillerato. La única institución postsecundaria a nivel subgraduado que ofrece programas en los niveles de grado asociado (33.3\%) y bachillerato $(35.7 \%)$ es el Sistema de la UIPR. Cuatro instituciones universitarias ofrecen el $28.6 \%$ de los programas a nivel de maestría en Finanzas: Bayamón Central University (100.0\%), Sistema de la PUC (66.7\%), Sistema de la UIPR (50.0\%) y el Sistema de la UPR (20.0\%). A nivel graduado el único programa doctoral en Puerto Rico se ofrece en la UPR, Recinto de Río Piedras; este es el doctorado en Administración de Empresas con especialidad en Finanzas.

Tabla 3

Distribución porcentual de programas académicos relacionados con la profesión de finanzas de acuerdo al nivel académico en instituciones de educación superior en Puerto Rico desde 1903 hasta 2011

\begin{tabular}{|c|c|c|c|c|c|}
\hline \multirow[b]{2}{*}{$\begin{array}{l}\text { Nombre de la } \\
\text { institución }\end{array}$} & \multicolumn{2}{|c|}{ Subgraduado } & \multicolumn{2}{|c|}{ Graduado } & \multirow{2}{*}{$\begin{array}{c}\text { Total de } \\
\text { programas } \\
\text { académicos }\end{array}$} \\
\hline & $\begin{array}{c}\text { Grados } \\
\text { Asociados }\end{array}$ & $\begin{array}{l}\text { Bachille- } \\
\text { ratos }\end{array}$ & $\begin{array}{l}\text { Maes- } \\
\text { trías }\end{array}$ & $\begin{array}{c}\text { Docto- } \\
\text { rados }\end{array}$ & \\
\hline $\begin{array}{l}\text { Bayamón Central } \\
\text { University }\end{array}$ & 0.00 & 0.00 & 8.33 & 0.00 & 2.38 \\
\hline Caribbean University & 64.29 & 0.00 & 0.00 & 0.00 & 21.43 \\
\hline $\begin{array}{l}\text { Instituto de Banca y } \\
\text { Comercio }\end{array}$ & 14.29 & 0.00 & 0.00 & 0.00 & 4.76 \\
\hline $\begin{array}{l}\text { National University } \\
\text { College }\end{array}$ & 0.00 & 13.33 & 0.00 & 0.00 & 4.76 \\
\hline $\begin{array}{l}\text { Sistema de la } \\
\text { Pontificia Universidad } \\
\text { Católica }\end{array}$ & 0.00 & 6.67 & 16.67 & 0.00 & 7.14 \\
\hline $\begin{array}{l}\text { Sistema Universidad } \\
\text { de Puerto Rico }\end{array}$ & 0.00 & 46.67 & 16.67 & 100.00 & 23.81 \\
\hline $\begin{array}{l}\text { Sistema Ana G. } \\
\text { Méndez }\end{array}$ & 0.00 & 6.67 & 0.00 & 0.00 & 2.38 \\
\hline $\begin{array}{l}\text { Sistema de la } \\
\text { Universidad } \\
\text { Interamericana }\end{array}$ & 21.43 & 26.67 & 58.33 & 0.00 & 33.33 \\
\hline Total & 100.00 & 100.00 & 100.00 & 100.00 & 100.00 \\
\hline
\end{tabular}

Fuente: Consejo de Educación Superior de Puerto Rico. 
La Tabla 3 muestra la distribución porcentual de los programas académicos de las finanzas por niveles académicos. Tres instituciones tienen 33 de los 42 ofrecimientos, para un $78.6 \%$ de los programas académicos. Estas tres son el Sistema de la UIPR con un $33.3 \%$ (14 programas), el Sistema de la UPR con un $23.8 \%$ (10 programas) y Caribbean University con un $21.4 \%$ (9 programas). A nivel subgraduado, 3 instituciones universitarias ofrecen unos 14 programas académicos en grados asociados: Caribbean University con un $64.2 \%$ (9 programas), el Sistema de la UIPR con un $21.4 \%$ (3 programas) y el Instituto de Banca y Comercio con un $14.3 \%$ (2 programas). Cinco instituciones ofrecen 15 programas académicos a nivel de bachillerato; el $73.4 \%$ se encuentra en dos sistemas universitarios: el Sistema de la UPR con un 46.6\% (7 programas) y el Sistema de la UIPR con un $26.6 \%$ (4 programas). A nivel de maestría, dos sistemas universitarios ofrecen un $79.9 \%$ de los programas académicos. Estos nueve programas académicos se concentran en el Sistema de la UIPR con un 58.3\% (7 programas) y el Sistema de la PUC con un $16.6 \%$. Estas últimas instituciones postsecundarias ofrecen dos programas académicos a nivel de maestría, respectivamente.

Los datos presentados demuestran la oferta que la academia ofrece al mercado laboral. Se requieren estudios posteriores que puedan evidenciar si existe integración entre la oferta y la demanda para que las instituciones públicas y privadas puedan establecer un lineamiento para el desarrollo económico de Puerto Rico. Además, nos llama la atención que la profesión promueve la obtención de certificaciones y licenciamientos, que requieren una preparación académica rigurosa de gran cantidad de análisis para la toma de decisiones. Nos preguntamos si las instituciones están atemperando estas exigencias del mercado laboral en sus ofertas académicas. A continuación presentaremos los datos relacionados con el desarrollo de la profesión de las finanzas por ocupación en Puerto Rico. 


\section{DeSARROLlo de LA PROFESIÓN DE FINANZAS POR OCUPACIÓN}

Otro de los objetivos del estudio es analizar el desarrollo de la profesión de las finanzas en Puerto Rico desde 1898 hasta 2010. Las Tablas 4 y 5 muestran la proporción de empleos por décadas vis a vis la cantidad del total de empleos, la cantidad de empleos generados y la tasa de crecimiento en Puerto Rico. Los datos recopilados comprenden 13 censos de 1898 a 2010. Encontramos que en el 1898 la ocupaciones relacionadas con las finanzas representaban una proporción de $1.27 \%$ (unos 4,017 empleos). Estos datos concuerdan con lo expuesto en la revisión de literatura sobre el desarrollo del sistema financiero a finales del siglo XIX; el surgimiento de la banca (1877); y principios del XX, con la estabilización de la moneda (Acta Orgánica de 1900). Estos empleos se concentraban en bienes raíces, banca, cobro, etc. Más tarde, la proporción bajó a $0.13 \%$ (unos 413 empleos) por los cambios en las definiciones de la ocupaciones y el nivel de desagregación de las mismas.

A partir de 1910 hasta 1935 hubo un aumento en las proporciones de $0.13 \%$ a $0.31 \%$ (de 493 a 1,629 personas empleadas). Esto respondió a que las instituciones bancarias establecidas aumentaron el volumen de negocios y el uso de las facilidades financieras en Estados Unidos, (Di Venuti, 1950, p. 25). Mencionamos en la revisión de literatura que el Tesorero Insular de Puerto Rico informó en 1919 la existencia de 236 corporaciones domésticas y 150 extranjeras, entre las cuales 16 eran bancos.

Los datos de los censos de 1930, 1935 y 1940 evidenciaron una reducción proporcional de $0.37 \%$ (censo de 1930 ) a $0.13 \%$ (censo de 1940), reduciéndose en 1,188 empleos. Debemos mencionar que los censos se realizan cada 10 años; sin embargo, por circunstancias particulares al territorio de Puerto Rico se realizó un censo especial en 1935. Podemos identificar tres sucesos históricos con un impacto negativo en la economía como factores de la reducción de empleos: la caída de la Bolsa en 1929, el huracán San Ciprián en 1932 y la fragilidad de la industria del azúcar que desde 1920 bajó su precio hasta el 1937, con el Sugar Act que redujo su producción. 
A partir de 1940, hasta 2010, la proporción de personas empleadas en ocupaciones relacionadas con las finanzas incrementó de $0.13 \%$ a $2.14 \%$ (de 659 a 20,350 personas empleadas). Esto representó un aumento de 19,691 empleos. Este aumento de la fuerza laboral se debe a una estructura establecida de la banca para 1948, representada con 14 grupos variados de instituciones financieras (Di Venuti, 1950, p. 50), y en gran medida a los modelos de desarrollo económicos generados en Puerto Rico durante los periodos de 1950 al presente. Para finales de la década de 1950 al 1960 se habían promovido más de 500 plantas (filiales) y asistido a más de 80 para una inversión combinada de más de $\$ 500$ millones y una creación de 40,000 nuevos empleos. En la década de 1960 al 1970 existían unas 1,400 plantas las cuales eran responsables de dos terceras partes del empleo en la manufactura. Gran parte de las empresas que operaban durante los primeros años del programa eran industrias livianas de alto contenido de mano de obra.

Este desarrollo económico demuestra que la Isla necesitaba personal diestro especializado en las ocupaciones de las finanzas, con el objetivo de maximizar los recursos de las empresas. Además, los hallazgos evidenciaron que los años censales con las tasas de crecimientos más bajas en las ocupaciones fueron: tasa de -8.65 (1935, 218 empleos menos), $-1.25 \%$ (1930, 970 empleos menos) y -1.21 (2010, 2,634 empleo menos). Los autores de esta investigación recomendaron estudios futuros que midan y analicen las causas y el impacto de esta tendencia en el mercado laboral y en la oferta académica. Esta disciplina ha demostrado un crecimiento en el mercado laboral por los cambios, dinámicas y tendencias socioeconómicas, políticas, geográficas, tecnológicas y demográficas, entre otras. Esto es así, a pesar de que el mercado de este sector industrial tiene muchas exigencias en cuanto a las licencias y certificaciones en el contexto de ejercer la profesión en y fuera de Puerto Rico.

Durante la investigación comenzamos la identificación, la desagregación y el análisis de los datos por género, con el objetivo de evidenciar las tendencias y la participación de los hombres y las mujeres en las ocupaciones relacionadas con la profesión de las finanzas desde 1898 hasta 2010. 
Rivera Aponte, Cádiz Ocasio \& Gely Rojas

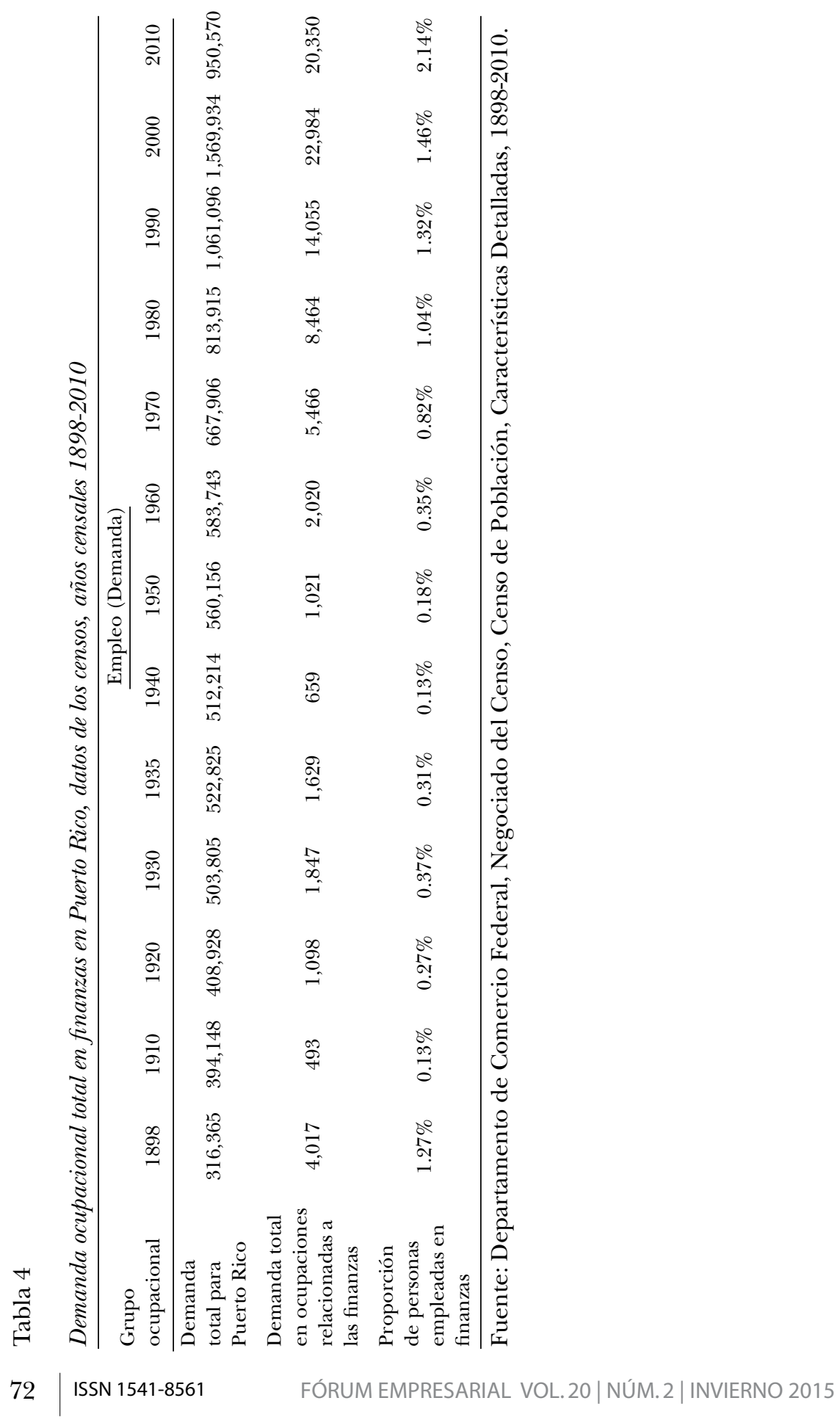




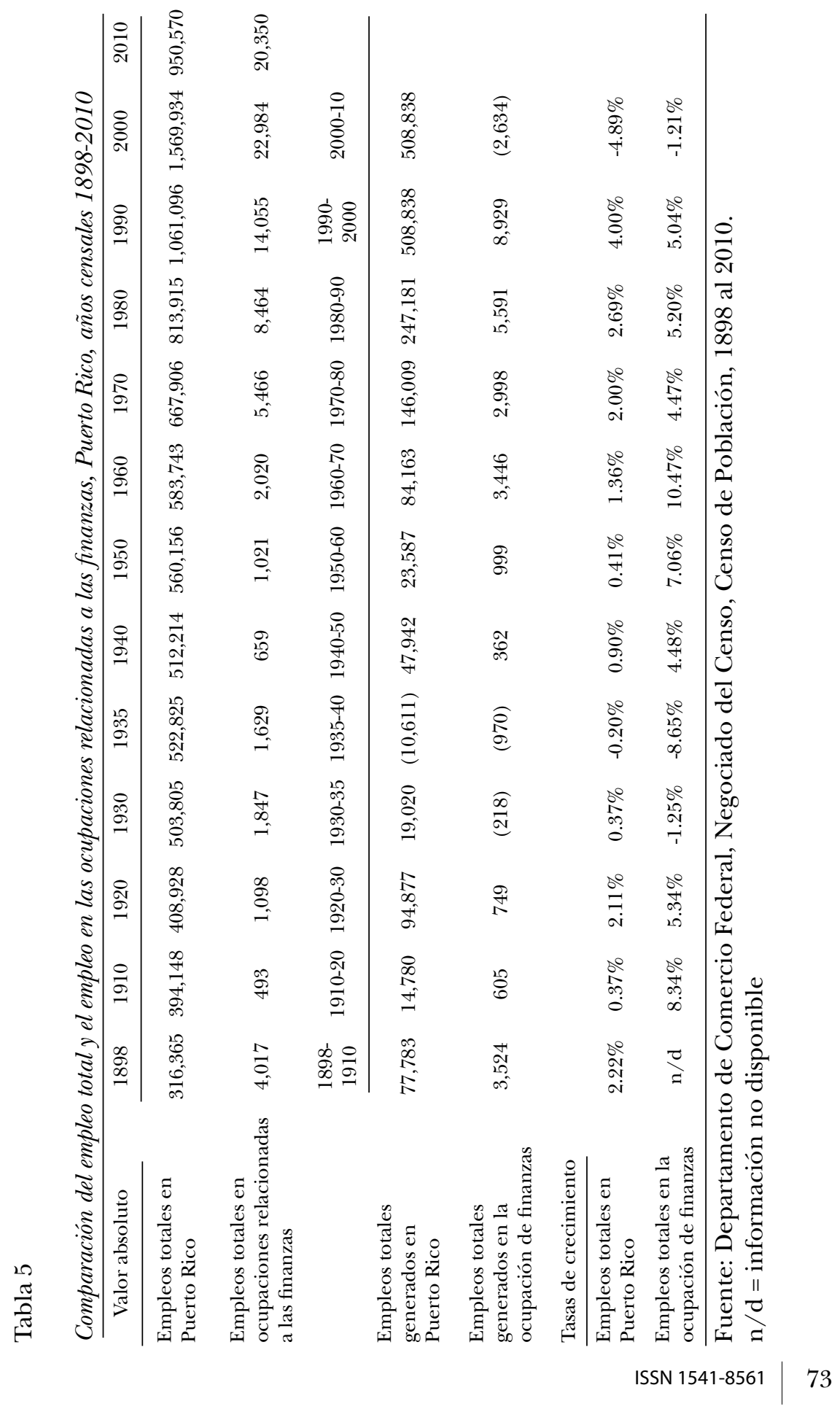


Rivera Aponte, Cádiz Ocasio \& Gely Rojas

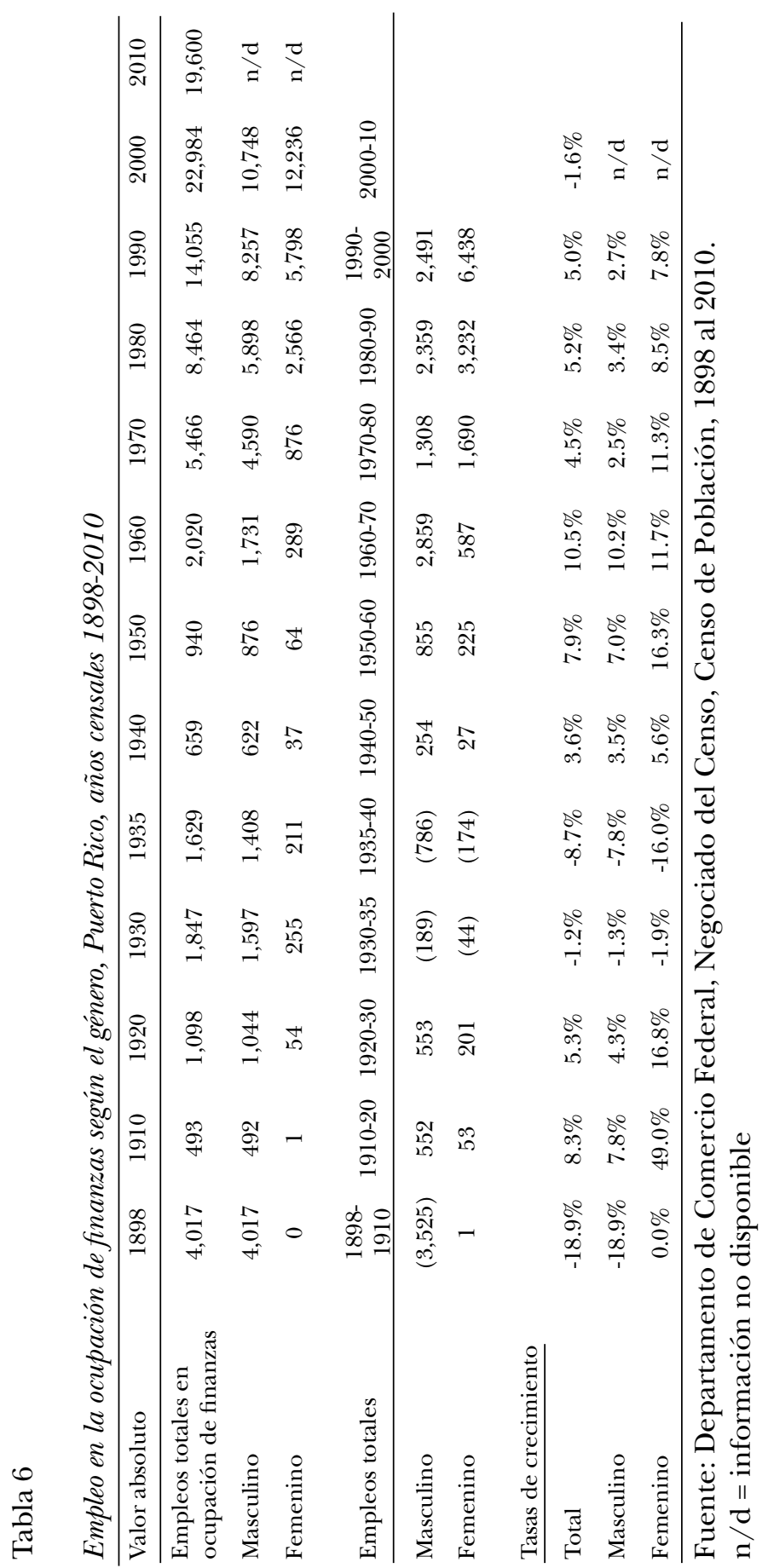




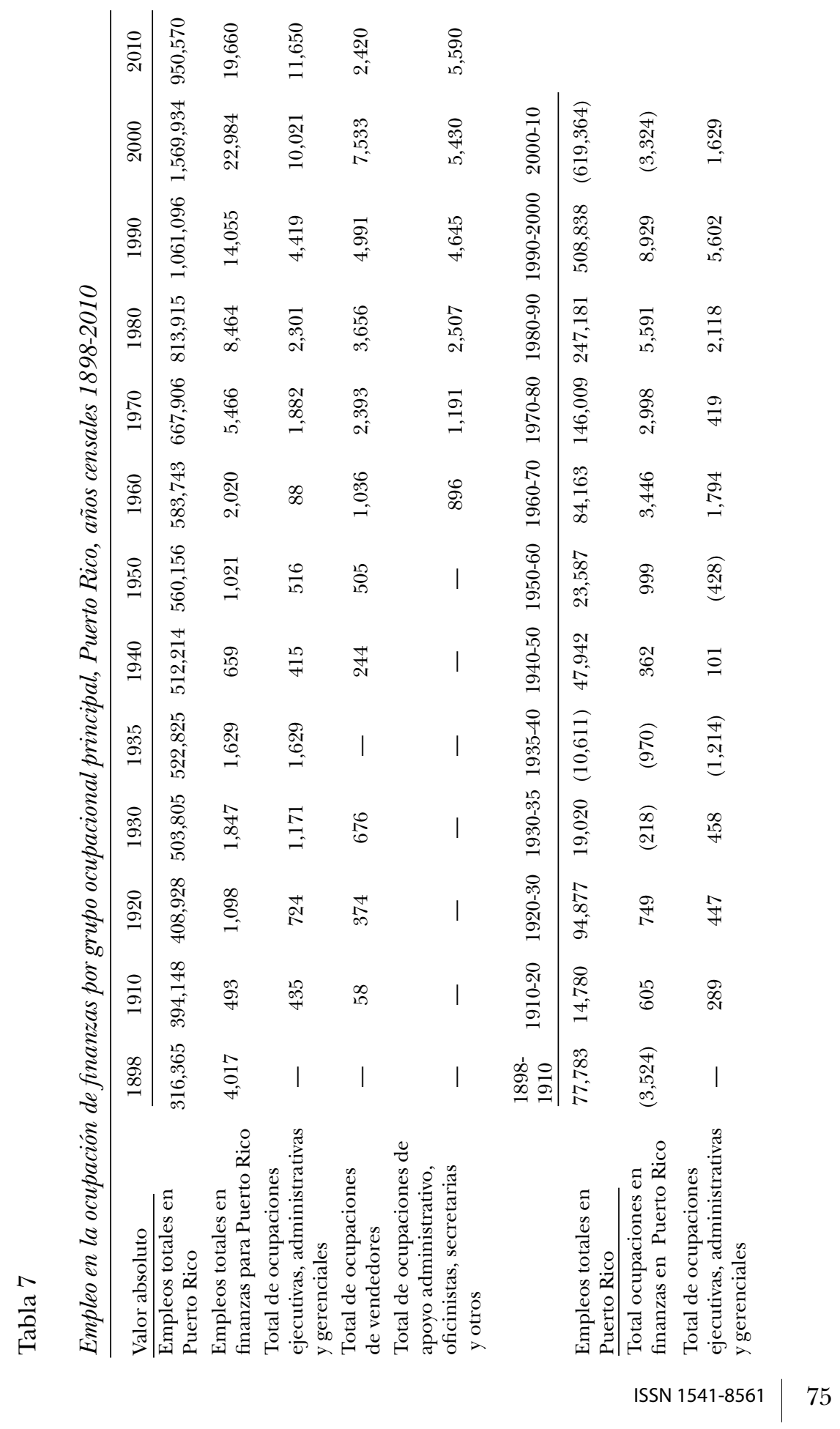




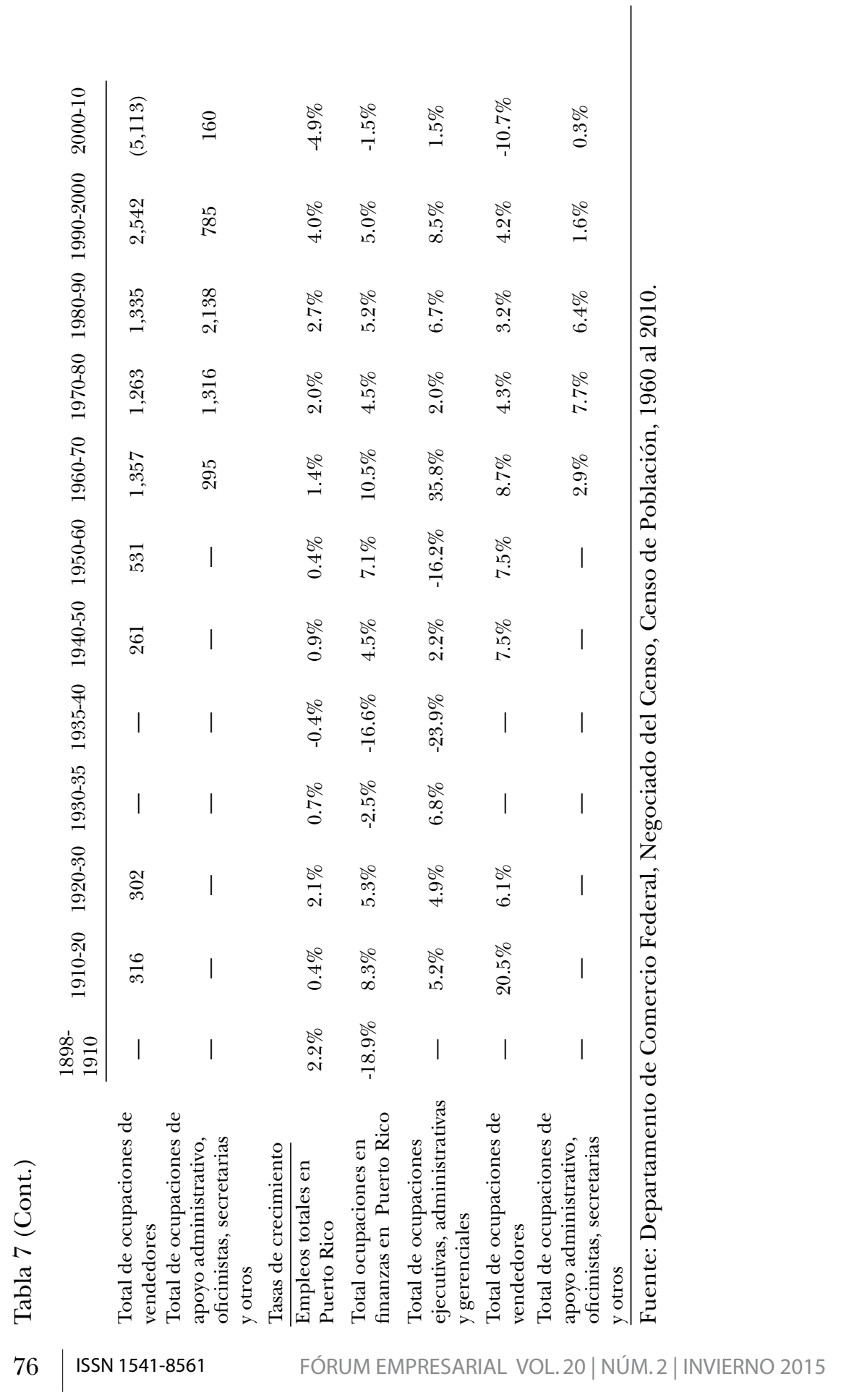


La Tabla 6, presenta los datos de empleo para la ocupación de finanzas desagregados por género de 1898 a 2000. Los datos totales evidenciaron que en 1898 existían 4,017 personas empleadas. En 1910 había unas 493 personas empleadas (periodo en que se redefinieron las agrupaciones) y en 1935 hubo un aumento con 1,629 personas empleadas. Durante 1935 a 1940 se reflejó una reducción a 786 empleos y a partir del 1940 al 2000 se generaron unos 22,325 empleos en Puerto Rico. En la década del 2000 al 2010 en Puerto Rico se perdieron unos 3,384 empleos en esta profesión. El desarrollo, el crecimiento y las pérdidas de empleos en las áreas de las finanzas son producto de las transformaciones exógenas de oportunidades y retos que enfrentó Puerto Rico antes y después de la invasión norteamericana.

$\mathrm{Al}$ estudiar e identificar estos datos y la relación por género encontramos que las ocupaciones de finanzas no están tan desagregadas en los libros de la clasificación de las ocupaciones de Puerto Rico en transcursos de la historia recogida e informada a través de cada década. En el 1898 había un total de 4,017 personas empleadas de las cuales $100.0 \%$ eran del género masculino. No es hasta los resultados del censo del 1910 cuando se observa la participación de la primera mujer en las ocupaciones de banqueros, corredores y prestamistas de dinero en el sector de bienes raíces, porque las ocupaciones estaban agregadas. A partir de esa década, el género femenino incrementó su participación en la fuerza laboral hasta dominar en el 2000. Los resultados más sobresalientes fueron: (1) la mayor tasa de crecimiento fue de $49.0 \%$ para 1910 al 1920, (2) desde 1940-1950 al 1990-2000 las tasas de crecimiento fluctuaron entre $5.6 \%$ a $16.3 \%$, (3) en las décadas de 1950-1960 se evidenció una crecimiento de $7.9 \%$ (periodo de la industrialización de Manos a la Obra), (4) en el periodo del 1990-2000 se generaron un total de 8,929 empleos de los cuales un $69.5 \%$ lo constituyó unas 6,213 mujeres empleadas en algunas de las profesiones relacionadas con las finanzas, (5) a partir del 1950-1960 al 2000 la tasas de crecimientos arrojaron que el género femenino mostraba una participación mayor vis a vis el género masculino, (6) desde los años de 1970-1980 participaban en la fuerza laboral y se generaron más 
empleos para el género femenino en la profesión de las finanzas, y (7) los datos de censo del 2000 evidenciaron que el género femenino dominaba las ocupaciones de finanzas en Puerto Rico.

Por otra parte, los datos del género masculino mostraron un comportamiento de crecimiento y dominio desde 1898 hasta el 1990 en las ocupaciones de finanzas. También encontramos que en la década de 1930 al 1940 (Segunda Guerra Mundial) bajó la participación laboral del género masculino en la ocupaciones y en 1980-1990, la tasa de crecimiento en el género masculino continúa reduciéndose de $3.4 \%$ a $2.7 \%$ (1990-2000).

La Tabla 7 muestra la cantidad de empleos en la ocupación de finanzas por grupo ocupacional principal para Puerto Rico desde 1898 al 2010. La profesión de finanzas se agrega en 3 de los 13 grupos ocupacionales principales. Estos grupos ocupacionales son: (1) los ejecutivos, administradores y gerenciales, (2) los vendedores y (3) apoyo administrativo, oficinistas y secretarios, entre otros. A partir de la década de 1960 a 1970, los datos demuestran que las ocupaciones de las finanzas en Puerto Rico arrojaron una tasa de crecimiento de $10.5 \%$, generando unos 3,446 empleos. Para estos años de 1960 a 1970, los grupos ocupacionales principales de mayor crecimientos fueron: (1) los ejecutivos, administradores y gerenciales con una tasa de crecimiento de $35.8 \%$ (generando unos 1,794 empleos), (2) los vendedores con una tasa de crecimiento de 8.7\% (generando unos 1,357 empleos) y (3) apoyo administrativo, oficinistas y secretarios con una tasa de crecimiento de $2.9 \%$ (generando unos 295 empleos). Este comportamiento ha ido variando por los comportamientos y tendencias de los sectores industriales (públicos, privados y las organizaciones sin fines de lucro).

En Puerto Rico el periodo que comprende desde el 2000 al 2010 cambió la tendencia en las ocupaciones relacionadas con las profesiones de las finanzas. La Isla atravesó y continúa teniendo situaciones inestables que afectan la participación y el generar empleos en el mercado laboral. Durante este periodo los datos del Censo de Puerto Rico indican que la tasa de crecimiento bajó en $-4.9 \%$. Esta reducción afectó a todos los sectores industriales y ocupacionales en la Isla. Una de las grandes caídas de los sectores industriales fue 
el cierre de varias industrias privadas, el sector de la banca, el gobierno y las bienes raíces, entre otros.

Lo antes expuesto evidenció que, durante el periodo del $2000 \mathrm{al}$ 2010, el grupo ocupacional principal relacionado a las finanzas que más empleos había perdido era el que agregaba las ocupaciones de los vendedores (entre estas se encuentran las ocupaciones de ventas de seguros, bienes raíces, estimadores de costos, entre otras). En la década del 2000 y 2010 se evidenció una reducción 5,133 empleos con una tasa de crecimiento de $-10.7 \%$. Este comportamiento se ha evidenciado en todas las áreas relacionadas con ventas en Puerto Rico. De aquí surgen preguntas para otros estudios. ¿En cuál de los géneros se ha perdido más empleos en el área de las ventas? ¿Cuál es el comportamiento por género para otros grupos ocupacionales que se encuentran las ocupaciones de las finanzas en Puerto Rico?

\section{BRECHA SALARIAL EN OCUPACIÓN DE FINANZAS}

El último objetivo de estudio en esta investigación es analizar las tendencias en el salario promedio por género y establecer si existe o no una brecha salarial en las ocupaciones relacionadas con las finanzas en Puerto Rico. La fuente de datos usada fue el Censo de Población de Puerto Rico para el año 2000 comparado con el análisis sobre brecha salarial planteado en el libro de Mujer y brecha salarial: Reto del siglo XXI (Rivera Aponte, Ruiz Mercado, \& García Toro, 2007). En esta parte, por la complejidad del estudio solamente se presentaron los datos de ingreso promedio por género y las ocupaciones relacionadas con la profesión de las finanzas para el año 2000.

En prácticamente todos los países del mundo existe una diferencia entre el salario que se le paga a la mujer y al hombre. Esta brecha se ha reducido en los últimos 50 años; sin embargo, persiste. Se han ofrecido varias explicaciones para este fenómeno, que varían desde factores culturales hasta la discriminación; por ejemplo, en Estados Unidos, todavía hay una brecha salarial (reducida por la Equal Pay Act) que no puede ser explicada por las características del tipo de trabajo que realizan los trabajadores del sexo masculino y del femenino. Después de mantenerse en alrededor de $60.0 \%$ desde la mitad 
de la década del 1950 hasta el 1960, la proporción de la mediana de la paga recibida por la mujer a la recibida por el hombre (Gender Pay Ratio) empezó a crecer en los últimos años de la década de 1960 al 1970 y alcanzó alrededor del 70.0\% para el 1990. En el 1997, el ratio había subido a $75.0 \%$ (Council of Economic Advisers, 1998); no obstante, es importante hacer mención que en las últimas cinco décadas la brecha salarial por género (BSG) se ha reducido.

El aumento en la experiencia acumulada por las mujeres en el mercado de trabajo y su movimiento hacia ocupaciones de paga más alta ha jugado un papel muy importante en el aumento de su salario promedio en relación con el hombre. Los cambios en el estatus familiar, la estructura industrial y las uniones sindicales también han sido factores que han contribuido a disminuir la BSG. A pesar de esta reducción, la brecha salarial persiste sin explicación. Muchos profesionales atribuyen esta brecha a la discriminación contra el sexo femenino en el mercado de trabajo. La evidencia de discriminación en el mercado laboral es muy difícil de determinar, por la diferencia en el ratio de paga femenina a paga masculina y cuánto se debe a preferencias y selección que hacen las mujeres y hacen los hombres. La diferencia no explicada en la brecha puede ser una medida indirecta y un tanto burda de la mencionada brecha por discriminación.

Algunos estudios han tratado de medir directamente este factor observando la diferencia de paga entre hombres y mujeres en tareas o trabajos similares o comparando la paga con medidas específicas de productividad. Estos estudios encuentran evidencia de discriminación en el mercado laboral y favorecen la conclusión de que las mujeres todavía enfrentan trato diferencial en los trabajos que realizan. La discriminación por género en la fuerza laboral puede tomar varias formas, desde prácticas que reducen las oportunidades de que la mujer sea empleada, hasta diferencias en la paga para hombres y mujeres que trabajan lado a lado haciendo el mismo trabajo e igualmente bien. Existe una variedad de teorías acerca de cómo y por qué la mujer enfrenta discriminación en el mercado laboral. Un determinado patrono puede no gustar de las empleadas del sexo femenino o subestimar sus habilidades; a los 
clientes de determinado negocio o empresa pueden no gustarle las empleadas mujeres, así como también los compañeros trabajadores del sexo masculino pueden resentir y resistir el trabajar con mujeres. Estas actitudes pueden no estar dirigidas a todos los empleados del sexo femenino, sino a aquellos que ocupan posiciones de alta jerarquía; por ejemplo, los trabajadores del sexo masculino pueden no objetar el tener a mujeres trabajando para ellos, pero sí pueden objetar cuando la mujer sea su superior. Además, los empleadores pueden enmarcarse en lo que se conoce como discriminación estadística, que quiere decir que ellos suponen que una mujer posee las características promedio de todas las mujeres; por ejemplo, debido a que la mujer en promedio tiene más alta tasa de cambio en el trabajo que los hombres, los empleadores pueden suponer que un determinado candidato del género femenino es más probable que deje la firma que un candidato del género masculino. La discriminación estadística, como otras formas de discriminación, es ilegal en prácticamente todos los países. A un patrono se le requiere que base la decisión de emplear y el pago a un trabajador sobre información específica acerca del individuo y no sobre presunciones basadas en género. Los hallazgos de Rivera Aponte, Ruiz Mercado y García Toro (2007) sobre la brecha salarial en Puerto Rico demostraron que existe una brecha salarial en Puerto Rico que está reduciéndose; sin embargo, no se encontró su causa.

La Tabla 8 muestra el ingreso promedio por género y ocupación de las finanzas para la década del 2000. La misma demuestra una brecha de salario que sobrepasa el $18.7 \%$. Encontramos que existe una brecha marcada en la ocupación por los diferentes grupos ocupacionales principales. Las mayores brechas salariales en las finanzas están en el grupo ocupacional principal de los vendedores con una brecha de salario de $28.9 \%$; en las ocupaciones de apoyo administrativo esta alcanza un $25.5 \%$; y en la ocupaciones de ejecutivas, administrativas y gerenciales la misma es de un $18.7 \%$. Dado a este comportamiento sería fundamental determinar en otros estudios cuáles sectores industriales tienen la mayor brecha salarial en la profesión de las finanzas y si existen más mujeres que hombres ejerciéndola dentro del mercado laboral. 


\section{Tabla 8}

Ingreso promedio por género y ocupación de finanzas, Puerto Rico, año 2000

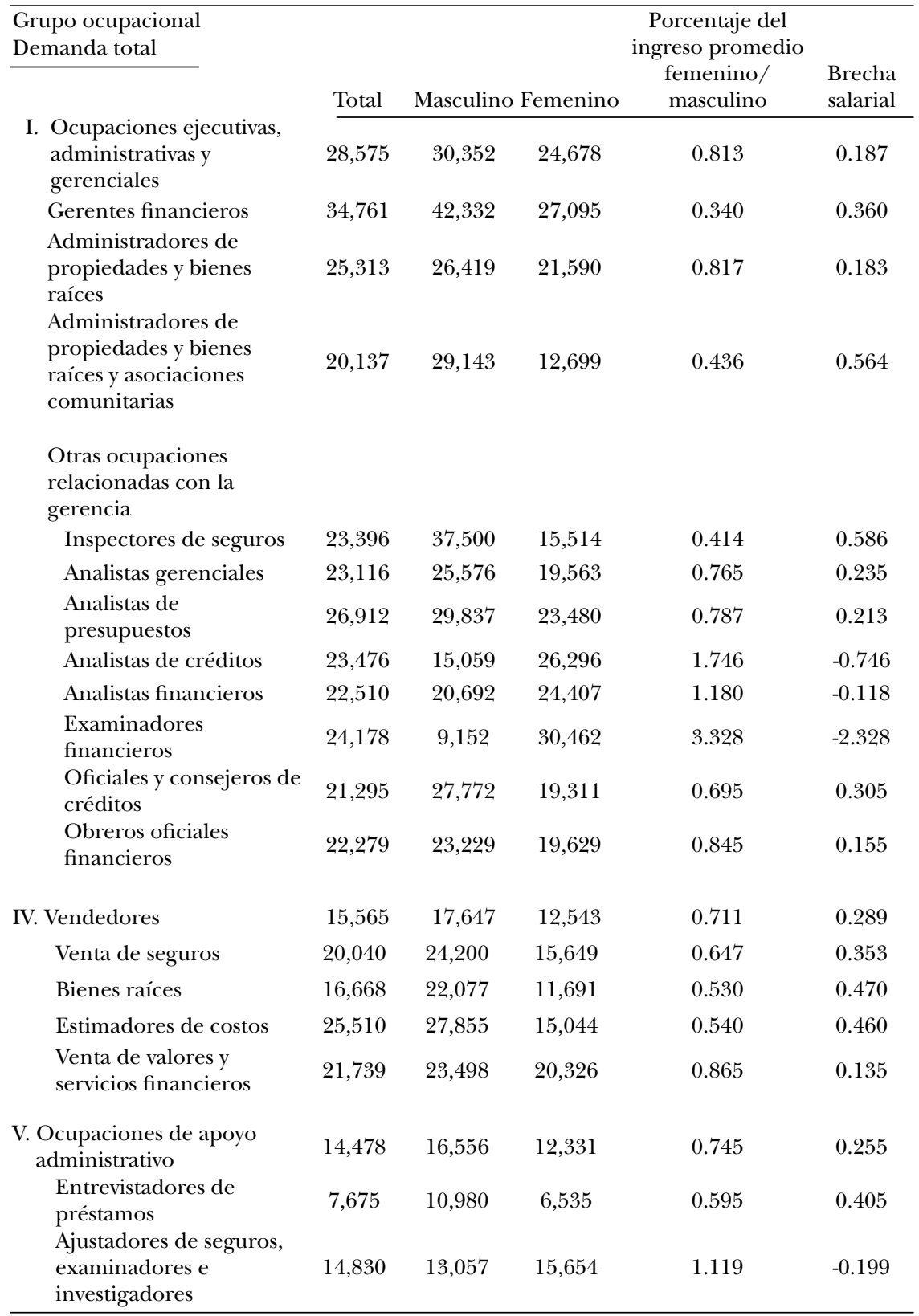
de Población, Características Detalladas, Advanced Query System, 2000. 


\section{Conclusiones}

Entre los hallazgos de este estudio encontramos, en las estadísticas del Censo de Puerto Rico, una fuerza laboral en la ocupación de finanzas de 4,017 empleados para 1898, constituida por el género masculino. Después de 1898, las ocupaciones de banqueros, corredores, prestamistas, colectores y bienes raíces se fueron desagregando en una gama de ocupaciones debido a su riqueza y complejidad dentro del mercado laboral y los sectores industriales. La primera mujer que trabajó en el campo de las finanzas fue en 1910. La primera institución académica que ofreció cursos de la disciplina como parte de la economía fue la Universidad de Puerto Rico, en Río Piedras, en el Colegio de Ciencias Sociales. Luego, la misma institución fue la pionera en generar un programa subgraduado a nivel de bachillerato en Finanzas, como disciplina independiente a partir de 1964, en el Colegio de Administración de Empresas. Actualmente hay 8 instituciones de educación superior que ofrecen 47 programas académicos relacionados con la disciplina de finanzas.

En la década de 1960, se comenzó a dar la oportunidad a las mujeres de incursionar en la educación superior del País mediante vales educativos. Así, estas empezaron a diversificar los campos de estudio, adentrándose en ocupaciones que estaban dominadas por el género masculino. Las mujeres comenzaron a incursionar en el comercio y hoy día existe un mayor número de mujeres en comparación con hombres que estudian la disciplina de finanzas, en las instituciones públicas y privadas del País. Las mujeres siguen dominando el mercado laboral en áreas de análisis y en posiciones administrativas y ejecutivas, principal grupo ocupacional de las finanzas. Al 2010, el campo de las finanzas es dominado por las mujeres en Puerto Rico, mayormente en el sector industrial de la banca. Por otro lado, la mayoría de las ocupaciones de finanzas se encuentran en los principales grupos ocupacionales de los puestos: (1) gerenciales, administrativos, ejecutivos y profesionales, (2) vendedores y (3) ocupaciones de apoyo administrativo. El campo de las finanzas evidenció un comportamiento de crecimiento en la 
generación de empleos en los sectores industriales en la Isla. Además, se constató que en el censo del 2000 existe una diferencia de brecha salarial en la mayoría de las ocupaciones relacionadas con las finanzas, en contra del género femenino.

\section{Recomendaciones}

Dado las exigencias y cambios del mercado laboral estudiado, recomendamos realizar estudios posteriores sobre la planificación de los recursos humanos en la ocupación de finanzas, para integrar la oferta y la demanda. También se recomienda a las instituciones de educación superior que se atemperen a los cambios y exigencias de la disciplina, ya que en las últimas décadas este campo es más regulado por licenciamientos, certificaciones y requisitos mínimos para ejercerlo. Entre las exigencias podemos mencionar las siguientes: Certified Financial Planner (CFP), Chartered Financial Analyst (CFA), Certified Fund Specialist (CFS), Chartered Investment Counselor (CIC), Serie 6, Serie 7, entre otras.

Por otra parte, identificamos la necesidad de estudios de benchmarking relacionados con la oferta y la demanda de las finanzas, tanto en territorios estadounidenses e internacionales, como método de atemperar los currículos de las instituciones de educación superior de Puerto Rico con las tendencias de Estados Unidos y del contexto global. Sugerimos estudios sobre cuáles sectores industriales se agregan más al género femenino y masculino, para identificar las posibles causas de la brecha salarial en la ocupación de finanzas y estudiar cómo se comportan las ocupaciones vis a vis los salarios en cada sector industrial en Puerto Rico. Por último, recomendamos la generación y normalización de bases de datos sobre cada uno de los componentes presentados en este estudio, para agilizar la búsqueda de alternativas por disciplina académica y ocupacional, y que estas puedan ofrecer un nivel de desagregación mayor que los datos del Censo para Puerto Rico. 


\section{RefERENCIAS}

Barron, J., \& Miranti, P. (1997). A history of corporate finance. Cambridge, UK: University Press.

Consejo de Educación Superior. Oficina de Estadísticas. (2011). Estadísticas de educación superior. Recuperado de http://www.ce.pr. gov/

Council of Economic Advisers. (1998, June). Explaining trends in the gender wage gap. Recuperado de http:/ / clinton4.nara.gov/WH/ EOP/CEA/html/gendergap.html

Del Valle, S. C., \& Schemel, M. E. (2011). Desarrollo y evolución de las finanzas. Acta Odontológica Venezolana, 49(1). Recuperado de http://www.actaodontologica.com/ediciones/2011/1/art19. asp\#top

Denzin, N. K., \& Lincoln, Y. S. (Eds.). (2008). Strategies of qualitative inquiry (3a ed.). Thousand Oaks, CA: Sage.

Di Venuti, B. (1950). Money and banking. Río Piedras, PR: University of Puerto Rico Press.

Elosua, M. (Ed.). (2007). Diccionario de empresa y economía. Madrid: LID Editorial Empresarial.

Enciclopedia financiera. (2015). Sistema financiero. Recuperado de http://www.enciclopediafinanciera.com/sistemafinanciero/ componentessistemafinancier o.htm

Finel-Honigman, I. (2010). A cultural history of finance. London: Routledge.

Maldonado, R. (1970). The role of the financial sector in the economic development of Puerto Rico. Washington, D.C.: Federal Deposit Insurance Corporation.

Martínez Soto, A. P. (2012). Los orígenes del crédito y las instituciones bancarias en Puerto Rico 1814-1878: Mitos, proyectos y fundaciones. Revista de la Historia de la Economía y de la Empresa, 6, 219-254.

Miller, M. H. (1999). The history of finance. Journal of Portfolio Management, 25(4), 95-101.

Oficina del Registrador, Recinto de Mayagüez. Glosarios, s.f. Recuperado de http://www.uprm.edu/registrar/glossary2.php 
Oliverio, M. E. (2007). Finance: Historical perspectives. In Encyclopedia of Business and Finance (2nd ed.). (Vol. 1 A-I). Detroit, MI: Thompson.

Pressman, S. (1999). Irving Fisher (1867-1947). En Fifty major economists. New York, NY: Routledge.

Rivera Aponte, Á. L., Ruiz Mercado, A. L., \& García Toro, V. I. (2007). Mujer y brecha salarial: Reto del siglo XXI. San Juan, PR: Oficina de la Procuradora de la Mujeres.

Rivera Aponte, Á. L. (2006). Cambios en la estructura industrial y ocupacional del empleo en el proceso de desarrollo económico de Puerto Rico: Análisis histórico de la planificación de los recursos humanos usando el Modelo de Insumo-Producto del 1960 al 2000. (Tesis inédita de doctorado). Universidad Interamericana de Puerto Rico, San Juan, Puerto Rico.

Rivera Rodríguez, I. (1991). El debate sobre el peso mexicano en Puerto Rico: 1879-1889. Río Piedras, PR: Unidad de Investigaciones Económicas, Departamento de Economía.

Roque Delgado, A. (1976). La contabilidad financiera: Su origen, su desarrollo y su impacto en la sociedad. Manuscrito inédito, Universidad de Puerto Rico, Recinto de Río Piedras.

Ruiz Mercado, A. L. (1986). Requerimiento de recursos humanos por ocupación y sector industrial, años 1984-1990. San Juan, PR: Puerto Rico Occupational Information Coordinating Committee.

Santiago de Curet, A. (1989). Crédito, moneda y bancos durante el siglo XIX. Río Piedras, PR: Editorial de la Universidad. 